\title{
RELAÇÕES DE PODER E RESISTÊNCIAS NA GESTÃO TERRITORIAL DAS BACIAS HIDROGRÁFICAS NO ESTADO DO PARANÁ.
}

\author{
Paulo César Medeiros* \\ Naldy Emerson Canali**
}

\section{Resumo}

A presente comunicação objetiva explicitar o Sistema Estadual de Recursos Hídricos do Paraná, revelando os atores e as territorialidades que emergem na implementação do atual modelo de gestão das águas na escala estadual. Tendo como base a Lei Federal no 9.433/97 - Política Nacional de Recursos Hídricos ou Lei das Águas e a Lei Estadual 12.726/99 - Política Estadual de Recursos Hídricos, observa-se que no modelo gerencial adotado, os órgãos governamentais de recursos hídricos devem abrir mão de sua autonomia administrativa sobre a gestão de águas para compartilhá-la com a nova instância deliberativa, representada pelos Comitês de Bacia Hidrográfica. O estudo das relações de poder resistências entre diversos atores e segmentos do poder público, dos usuários da água e da sociedade civil organizada permite analisar a gestão hídrica na perspectiva do desenvolvimento territorial das bacias hidrográficas.

PALAVRAS-CHAVE: COMITÊS DE BACIA HIDROGRÁFICA - RELAÇÕES DE PODER - TERRITÓRIO TERRITORIALIDADES - RESISTÊNCIAS

\section{RELATIONS OF POWER AND RESISTANCE IN TERRITORIAL MANAGEMENT OF CATCHMENT AREAS IN THE STATE OF PARANA.}

\begin{abstract}
This Communication aims to clarify the State System of Water Resources of Paraná showing the territoriality and the actors that emerge in the implementation of the current model of water management at state level. Based on Federal Law 9.433/97 - National Policy of Water Resources or the Water Law and State Law 12.726/99 - State Policy on Water Resources, it is observed that the administrative model used, the government departments of water resources should open hand of their administrative autonomy over the management of water to share it with the new body represented by the deliberative Watershed Committees. The study of power relations resistances among diverse stakeholders and segments of public power, water users and civil society organizations allows us to analyze water management from the perspective of territorial development of river basins.
\end{abstract}

KEY WORDS: WATERSHED COMMITTEE - RELATIONS OF POWER - TERRITORY - TERRITORIAL RESISTANCE

\footnotetext{
*Licenciado e Bacharel em Geografia pela UFPR. Doutor e Mestre em Geografia pela UFPR. Professor da Rede Particular de Ensino Superior e da Rede Pública do Estado do Paraná. Pesquisador. paulomedeiros@seed.pr.gov.br

* Licenciado e bacharel em geografia - UFPR -1965. Mestre em Geografia Física - USP - 1981 Doutor em Geografia - UNESP - 1991. Professor Senior da UFPR - Orientador da Pesquisa. naldy@brturbo.com.br
} 


\section{INTRODUÇÃO}

A partir da Constituição Brasileira de 1988, a questão das águas doces recebe uma nova leitura, a partir da qual, são definidas leis, atos administrativos que determinam novas diretrizes para a União e os Estados Federados, deixando explícitas as competências de cada esfera em relação aos corpos d'água. Com base na Constituição Federal, em 8 de janeiro de 1997 foi sancionada a Lei Federal no 9.433 Política Nacional de Recursos Hídricos ou Lei das Águas - expressando literalmente o processo de incorporação da gestão da água ao processo de desenvolvimento humano e ambiental, e orientando a sua transversalização nas demais políticas públicas no país.

O Estado do Paraná, seguindo os modelos e premissas das leis federais, a Assembléia Legislativa decretou e sancionou em 1999, a Lei Estadual n० 12.726, que instituiu a Política Estadual de Recursos Hídricos e estabeleceu os fundamentos, objetivos e diretrizes para o funcionamento do Sistema Estadual de Gerenciamento de Recursos Hídricos. Ao poder público estadual determinou a competência da construção dos Comitês de Bacia e a garantia do funcionamento do Sistema de Gestão Estadual integrando diferentes atores e instâncias da gestão hídrica.

Os Comitês de Bacia Hidrográfica se estruturam com participação de representantes de organizações setoriais (Sociedade Civil - Poder Público - Usuários). Ao Poder Público reserva-se a participação de representações das diferentes instâncias ligadas aos recursos hídricos na área da bacia. Os demais setores são identificados a partir da comprovação de ação direta, indireta ou uso dos os cursos e reservatórios de água, na respectiva bacia.

A hipótese do estudo admite que no modelo gerencial adotado, os órgãos governamentais de recursos hídricos devem abrir mão de sua autonomia administrativa sobre a gestão de águas para compartilhá-la com a nova instância deliberativa representada pelos Comitês de Bacia Hidrográfica. Neste contexto, o estudo das relações de poder entre diversos atores e segmentos do poder público, dos usuários da água e da sociedade civil organizada permite uma abordagem territorial da gestão da água e representa uma forma analítica de interpretação das variáveis que formam e transformam o Território, na perspectiva da gestão hídrica.

\section{OBJETIVOS DO ESTUDO}

O objetivo deste estudo é a identificação dos segmentos que atuam nos Comitês de Bacia do Paraná, revelando os atores e as territorialidades que emergem na implementação do atual modelo de gestão das águas na escala estadual. As ações dos diversos atores e segmentos do poder público, dos usuários da água e da sociedade civil organizada nos comitês, possibilitam a produção de indicadores de avaliação do desenvolvimento territorial e aplicação de instrumentos de análise da qualidade da gestão da bacia hidrográfica, com vista ao cumprimento das metas e diretrizes estabelecidas nas políticas públicas vigentes.

\section{PROCEDIMENTOS METODOLÓGICOS}

Tendo por base o recente processo de implantação do modelo integrado e participativo no espaço paranaense, a metodologia do presente estudo constituiu-se da coleta de informações e fontes primárias (Atos e documentos oficiais Estadual-Regional; Atas, Resoluções e documentos oficiais dos Comitês de Bacia; Estudos e Diagnósticos das Bacias Hidrográficas, Plano Estadual de $\mathrm{RH}$; Planos de Bacias em elaboração), além de entrevistas com gestores do Sistema Estadual de $\mathrm{RH}$ e observações de reuniões do Conselho Estadual de $\mathrm{RH}$. Os documentos produzidos no conjunto dos comitês até então criados e integrados ao Sistema Estadual de Recursos Hídricos, permitiram conhecer o estado da arte do processo de gestão e definir o quadro geral dos atores envolvidos na pesquisa.

\section{REFERENCIAL TEÓRICO E CONCEITUAL 4.1. A Bacia Hidrográfica: Geossistema - Território - Paisagem \\ A complexidade da explicação dos} processos naturais e humanos relacionados à água 
reside na interpretação das diferentes dimensões que a envolvem e transpassam. Analisando-se alguns estudos geográficos atuais notou-se que estas dimensões aparecem em três campos de estudos relacionados com a temática da gestão das bacias hidrográficas, a saber:

a) Estudos dos Geossistemas: relações meios: biótico, abiótico e antrópico;

$\beta)$ Estudos das Paisagens: lugares, percepção individual e coletiva; .

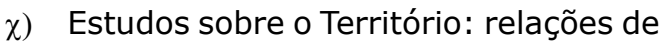
poder e configurações territoriais

A relação entre as bases teóricometodológicas em uso nestes campos de estudo permitiu definir uma estratégia para a explicação da gestão de águas, aplicando-se uma abordagem multidimensional da Bacia Hidrográfica, que considerou a proposta de análise apresentada por Georges Bertrand e Claude Bertrand. Conhecida como Sistema GTP - Geossistema-TerritórioPaisagem - esta abordagem resultou de estudos avançados, na década de 1990, sobre Meio Ambiente e introduziu uma nova metodologia de análise das políticas territoriais relativas ao tema "enraizando o meio ambiente no território e na história longa das sociedades", ao que denominaram "o retorno do geográfico".

Bertrand \& Bertrand (In. Passos (trad.p. 272) definem que um Sistema GTP:

[...] associa o geossistema-fonte ao território-recurso e à paisagemidentidade não tem outra razão de ser. É uma tentativa, de ordem geográfica, para matizar, ao mesmo tempo. A globalidade, a diversidade e a interatividade de todo o sistema ambiental. Ele não é um fim em si mesmo. É apenas uma etapa. O sistema GTP não substitui nada. Sua função essencial é de relançar a pesquisa ambiental sobre bases multidimensionais, no tempo e no espaço, quer seja no quadro de disciplinas ou mesmo em formas de construção da interdisciplinariedade.
Sua vocação primeira é favorecer uma reflexão epistemológica e conceitual e, na medida do possível, desencadear proposições metodológicas concretas.

Tomando a orientação dos autores, tendo clara a função e vocação desta abordagem, produziu-se uma análise relacional dos conceitos que formam o sistema GTP aplicando-se reflexões sobre a Gestão de Bacias Hidrográficas, na perspectiva da problemática em questão, o que possibilitou a organização de um Método de Trabalho e a estruturação teórico-metodológica da pesquisa.

O desenvolvimento de metodologias para o estudo do ambiente teve um avanço significativo com o surgimento da Teoria dos Sistemas. A Geomorfologia incorporou a teoria sistêmica inicialmente nos trabalhos de Strahler, no inicio dos anos 50 e influenciou vários estudiosos. A bacia hidrográfica passa a ser considerada, então, como um sistema aberto, que permite análises quantitativas e qualitativas. Neste sentido, segundo Christofoletti (1974, p. 02), alguns aspectos são importantes na compreensão do geossistema:

a) A Matéria - o material que será mobilizado (água, detritos, vegetação, rochas, solos, etc.);

b) A Energia - é a força inicial que leva ao funcionamento do sistema (energia potencial e energia cinética), a exemplo da gravidade que gera movimentos de materiais;

c) A Estrutura - constituída pelos elementos do sistema e suas relações, expressando-se através do arranjo de seus componentes, neste caso cada elemento pode tornar-se um sistema de acordo com a escala trabalhada.

Inicialmente temos o conceito de Geossistema, que introduzido na literatura soviética por Sotchava na década de 1960, com a preocupação de estabelecer uma tipologia aplicável aos fenômenos geográficos, enfocando aspectos integrados dos elementos naturais numa entidade espacial, em substituição aos aspectos da dinâmica biológica dos ecossistemas. Christofoletti (1999)

Para Sotchava (1977), os geossistemas apresentam-se como fenômenos naturais, no 
entanto, todos os fatores econômicos e sociais, influenciam sua estrutura e peculiaridades espaciais. Estas formações naturais experimentam, sob certa forma, o impacto dos ambientes social, econômico e tecnogênico. Assim, para este autor a principal concepção do geossistema é a conexão da natureza com a sociedade humana.

Nessa mesma linha de análise, Bertrand (1972), entende o Geossistema como um nível na escala espaço-temporal da análise da paisagem, que corresponde a dados ecológicos relativamente estáveis, resultante da combinação de fatores geomorfológicos, climáticos e hidrológicos, em combinação dinâmica em uma porção do espaço, portanto instável, de elementos físicos, bióticos e antrópicos, inter-relacionados "dialeticamente" entre si, desse modo fazendo da paisagem um conjunto único e indissociável em perpétua evolução.

Nesta perspectiva, o geossistema é concebido como sendo um composto de três subsistemas: o meio abiótico, a exploração biológica e a ação antrópica. No trabalho Pour une histoire écologique de la France rurale, publicado em 1975, Bertrand faz um tratamento mais aprofundado ao fenômeno antrópico, dentro da concepção geossistêmica, dando uma importância fundamental a este, como elemento determinante na dinâmica e nas transformações históricas das paisagens rurais francesas, diferenciando-o de ecossistema, conceito formulado pelos teóricos das ciências biológicas.

A análise da bacia como geossistema permite o estabelecimento de balanços energéticos a partir conceitos espaciais (corológicos) ao passo que a paisagem exprime a história social, e estas por sua vez dão vida e forma ao Território. A paisagem, segundo esta abordagem emerge como um produto social historicizado que permite interpretar o espaço geográfico nos limites de um sistema de produção econômica e cultural. Está então posicionada como um mediador entre a sociedade e a natureza, seja como uma interpretação social da natureza e talvez, além, uma interpretação natural da sociedade .

A interação entre os sistemas naturais e humanos modela as paisagens de uma dada bacia hidrográfica ou, aplicando-se a noção de
Bertrand (1978), produz o "natural finalizado". Esta reflexão permite perceber que paisagem é intrinsecamente ligada à idéia de qualidade que se exprime a partir de um sistema de valor social. Neste aspecto, a qualidade da gestão da água de uma bacia hidrográfica pode ser vista como um instrumento que orienta o pesquisador a identificar como os atores, no longo prazo, valorizam-na socialmente, estabelecendo os processos de gestão, monitoramento dos recursos ambientais - naturais, econômicos e sócio-culturais.

As novas políticas públicas de gestão das águas garantem a participação dos setores públicos, civis e privados. Esta mudança de modelo gerencial, segundo o foco desta pesquisa, traduz o novo valor estratégico do Território se relaciona com a redefinição da natureza à nova forma de produzir. Portanto o tratamento da dimensão territorial da gestão da água é uma necessidade que se apresenta como primordial e revela o potencial de desenvolvimento de uma dada bacia hidrográfica, permitido conhecer as relações que formam e fluem nos sistemas sócio-espaciais.

\subsection{Bacias Hidrográficas: relações escalares e de poder na produção do Território.}

A Bacia Hidrográfica, uma vez definida como objeto de análise relativa à gestão das águas, adquire diferentes dimensões geográficas (geossistema-território-paisagem). Sua definição como unidade espacial estabelece também relações escalares na medida em que subdividem naturalmente em sub-unidades hidrográficas como sub-bacias e/ou micro-bacias. Considere-se ainda que sua gestão se dá em âmbito intra-setoriais produzindo escalas distintas (local, regional, estadual, nacional e global) e suas relações. Assim, pode-se avançar na idéia de que as relações escalares são relações de poder. A escala é tanto um objeto como um meio para as lutas econômicas e políticas que alteram e expressa trocas na produção da geometria do poder social na organização escalar de uma dada sociedade. As pessoas, mediante suas relações, seus hábitos, normas, costumes e instituições reproduzem certas pautas que permitem a convivência e um grau suficiente de consenso. Estas pautas têm formas espaciais particulares que podem acabar 
institucionalizando-se em formas espaciais que eventualmente permitem uma reprodução estável e a percepção do espaço geográfico.

Segundo González (2005) as escalas são construções sociais, não estão ontologicamente dadas de antemão, sejam elas urbanas, regionais, nacionais ou qualquer outra. Elas estão ligadas às suas origens, determinação e coerência interna, elas não existem sem as interações sociais, são a própria expressão destas relações.

Smith (2000) concebe a escala como uma resolução geográfica de processos sociais contraditórios de competição e cooperação. Deste modo, a produção e a reprodução contínuas da escala expressam tanto a disputa social quanto a geográfica para o estabelecimento das fronteiras em diferentes lugares, localizações e sítios de experiência. Segundo o autor "a construção do lugar implica a produção da escala, na medida em que os lugares são diferenciados uns dos outros; a escala é o critério de diferença, não tanto entre lugares como entre tipos diferentes de lugares".

Neste modo de análise, a Bacia Hidrográfica, do ponto de vista de sua conexão natural, social e política está imersa numa seqüência de escalas específicas que apresentam quatro características: Identidade, diferenças internas, fronteiras com "outras escalas" e resistências políticas. Estas características permitem conhecer interna e externamente uma determinada escala em suas múltiplas relações como as demais, ampliando o horizonte da análise geográfica contemporânea.

O poder se manifesta por ocasião da relação entre indivíduos e grupos de indivíduos , é um processo de troca ou de comunicação quando, na relação que se estabelece, os dois pólos fazem face um ao outro ou se confrontam. O campo da relação é um campo de poder que organiza os elementos e as configurações, e definem a natureza do poder. Segundo Raffestin (1993):

O poder não se adquire; é exercido a partir de inumeráveis pontos;

As relações de poder não estão em posição de exterioridade no que diz respeito a outros tipos de relações (econômicas, sociais, etc.), mas são imanentes a elas;

O poder vem de baixo; não há uma oposição binária e global entre dominador e ou dominados;

As relações de poder são, concomitantemente, intencionais e não subjetivas;

Onde há poder há resistência e, no entanto, ou por isso mesmo, esta jamais está em posição de exterioridade em relação ao poder.

O laço entre poder e o saber é evidente, mas não há nem informação pura nem energia pura. Trata-se sempre de uma combinação das duas. O espaço-tempo relacional é organizado pela combinação de energia e informação. Em outros termos, pode-se dizer que o poder, quanto aos meios mobilizados, é definido por uma combinação variável de energia e informação. Com esses dois elementos presentes, é possível dizer que há poderes com forte componente energético ou, inversamente, poderes com forte componente informacional.

O poder visa o controle e a dominação sobre os homens e sobre as coisas. Pode-se retomar aqui a divisão tripartida em uso na geografia política: a população, o território e os recursos. Considerando o que foi dito sobre a natureza do poder, será fácil compreender por que colocamos a população em primeiro lugar: simplesmente por que ela está na origem de todo o poder.

Segundo Ribeiro (2008) a apropriação da água pela espécie humana ocorre ao longo dos tempos e o controle dos estoques de água naturais, sejam subterrâneas ou nos rios, se deram por processos de apropriação dessa água por fatores históricos, sociais, políticos, que envolvem trocas comerciais, guerras, domínios territoriais. A abordagem política da Água busca mostrar de que maneira ocorreu a apropriação da água a partir das relações de poder.

No modelo gerencial adotado pelos instrumentos legais e institucionais em vigor, emergem atores individuais e coletivos uma vez que a representação dos diversos segmentos do poder público, usuários da água e sociedade civil organizada no Sistema de Gestão, permite a 
identificação e reconhecimento de suas práticas espaciais nas áreas de abrangência da gestão.

As práticas dos atores no processo de gestão da bacia são a expressão do Trabalho, energia ou empenho em garantir os interesses individuais e/ou corporativos e/ou setoriais, frente aos usos da água, permitindo conhecer e analisar relações de poder e resistência no processo de gestão do Território.

Os conhecimentos e técnicas empreendidas, bem como os modelos gerenciais e os instrumentos que regem o processo de gestão nos Comitês de Bacia, permitem decodificar indicadores e parâmetros de rendimento da gestão frente aos conflitos nos usos e a solução de problemas do desenvolvimento territorial.

\section{A GESTÃO TERRITORIAL DAS ÁGUAS NO ESPAÇO PARANAENSE}

\subsection{O Sistema de Gestão de Águas no} Estado do Paraná

A análise da Lei 9433/97 contribui com a elucidação dos processos políticos e institucionais pelos quais se oficializam as decisões referentes às políticas de gestão de águas. O Art. 37 da Lei das Águas define como áreas de atuação do Comitê de Bacia, a totalidade de uma bacia; a sub-bacia de tributário do curso principal e seus tributários; grupos de bacias ou sub-bacias contíguas. O Comitê adquire pela lei, as competências de: promover debates e a articulação das entidades intervenientes; arbitrar conflitos em primeira estância; aprovar o Plano de Recursos Hídricos da bacia e acompanhar sua execução, sugerindo providências; estabelecer valores e mecanismos de cobrança e discutir com o Conselho Nacional as isenções da outorga e custos de obras de usos múltiplos. Compõem este Comitê: representantes da União, Estados, Municípios, usuários e entidades civis com atuação na bacia.

A instalação de comitê de bacias hidrográficas no Estado do Paraná iniciou pelo do Alto Iguaçu e Afluentes do Alto Ribeira a até início de 2009 foram instalados mais quatro comitês (Tibagi, Jordão - Médio Iguaçu, Paraná 3, PirapóParanapanema 3 e 4). Cada comitê conta com a participação de representantes setoriais do governo, sociedade civil organizada (universidades e ONGs) e associações de usuários (captam ou lançam dejetos nos rios). Estes comitês mistos que devem deliberar sobre o que vai ser feito na bacia, inclusive os valores de arrecadação, os planos de aplicação dos recursos e a efetivação do Plano da Bacia.

O Sistema Estadual de Recursos Hídricos - SERH foi criado pela lei estadual no $12.726 / 99$ em sintonia com a legislação federal (lei 9433/97). Esta lei estadual institui ainda, a Política Estadual de Recursos Hídricos e propõe seus objetivos e a estrutura para sua implementação:

Objetivos:

a) Coordenar a gestão integrada das águas;

ß) Arbitrar administrativamente os conflitos relacionados com os recursos hídricos;

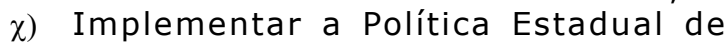
Recursos Hídricos (instituída pela lei acima mencionada);

6) Planejar, regular e controlar o uso, a preservação e a recuperação dos recursos hídricos e dos ecossistemas aquáticos do Estado;

ع) Promover a cobrança pelos direitos de uso de recursos hídricos (cobrança do uso da água);

Composição do Sistema:

a) Conselho Estadual de Recursos Hídricos (órgão deliberativo e normativo);

B) Secretaria de Estado do Meio Ambiente / SUDERHSA Superintendência Estadual dos Recursos Hídricos e Saneamento Ambiental (órgão gestor e coordenador);

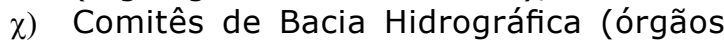
regionais e setoriais deliberativos e normativos de sua bacia hidrográfica específica);

ס) Agências de Bacias Hidrográfica (órgãos executivos)

Conselho Estadual de Recursos Hídricos:

É o órgão normativo e deliberativo do SEGRH do Paraná composto por representantes de instituições do Poder Executivo Estadual, com atuação relevante nas questões de meio ambiente, recursos hídricos e desenvolvimento sustentável; representantes dos Municípios e representantes das entidades da sociedade civil usuários; suas 
principais competências são:

a) Estabelecer os princípios para a Política Estadual de RH a serem observados pelo Plano Estadual de $\mathrm{RH}$,

ß) Aprovar o Plano Estadual de Recursos Hídricos, na forma da lei,

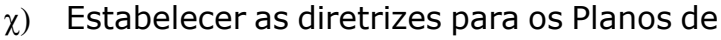
Diretores e os de Bacia Hidrográfica,

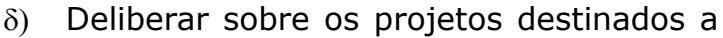
melhoria dos recursos hídricos,

ع) Estabelecer as normas gerais para a outorga e cobrança pelo uso da água.

Comitê de Bacia

Deve funcionar como um Conselho dos Recursos Hídricos da Bacia Hidrográfica. Seus membros estão geograficamente situados na bacia onde o comitê atua.

a) Composto por representantes de instituições públicas estaduais que atuam nas áreas ambientais, recursos hídricos e desenvolvimento sustentável, por representantes dos municípios, por representantes da sociedade civil que atuam na bacia com recursos hídricos e por representantes de usuários de recursos hídricos.

ß) Principais competências: aprovar o Plano de Bacia, acompanhar a execução do Plano de Bacia, propor critérios e normas gerais para a outorga dos direitos de uso dos recursos hídricos, aprovar proposição de mecanismos de cobrança pelos direitos de uso de recursos hídricos e dos valores a serem cobrados, estabelecer critérios e promover o rateio de custo das obras de uso múltiplo, de interesse comum ou coletivo.

\section{Agência de Bacia}

As agências de bacia hidrográfica são entidades jurídicas de direito privado, com autonomia financeira e administrativa, que atuarão como unidades executivas descentralizadas de apoio a um ou mais comitês de bacia hidrográfica e responderão pelo seu suporte administrativo, técnico e financeiro. É a arrecadação feita por meio da cobrança que suportará as despesas de implantação, custeio para manutenção técnica e administrativa das agências, a médio e longo prazo.
Como o processo de implementação das agências de bacia hidrográfica propriamente ditas é, do ponto de vista legal, bastante complexo, exigindo até mesmo instituição pelo Estado e autorização legislativa, existe uma tendência à equiparação de organizações civis de recursos hídricos a agência de bacia, passando, então, a ser denominadas entidades equiparadas, no âmbito estadual, e entidades delegatárias, no âmbito federal.

\section{OS COMITÊS DE BACIA HIDROGRÁFICA: ATORES E INSTITUIÇÕES LIGADAS ÀS ÁGUAS}

\subsection{Os Comitês de Bacia do Paraná: regulamentação e implantação \\ Os Comitês de Bacia Hidrográfica}

- $\mathrm{CBH}$, integrantes do Sistema Estadual de Gerenciamento de Recursos Hídricos - SEGRH/PR foram oficialmente regulamentados pelo decreto no 2315 de 17/07/2000, conforme o disposto no Art. 33, inciso III da Lei Estadual no 12.726/1999. As normas estabelecidas por este Decreto foram aprovadas em deliberação do Conselho Estadual de Recursos Hídricos - CERH/PR no mesmo ano de sua criação.

O decreto 2315/2000 definiu os Comitês de Bacia Hidrográfica como órgãos colegiados, vinculados ao Conselho Estadual de Recursos Hídricos - CERH/PR, com atribuições normativas, deliberativas e consultivas, a serem exercidas em sua área de atuação e jurisdição, podendo ser instituídos em bacias ou sub-bacias hidrográficas de rios de domínio do Estado do Paraná, ou em sub-bacias de rios de domínio da União, cuja gestão a ele tenha sido delegada.

Segundo o decreto a instituição formal de um Comitê de Bacia Hidrográfica será efetivada por decreto governamental, mediante prévia solicitação do Conselho Estadual de Recursos Hídricos - CERH/ PR. A proposição de instituição de Comitê de Bacia Hidrográfica poderá ser encaminhada à consideração do Conselho Estadual de Recursos Hídricos - CERH/PR quando subscrita por, no mínimo, três órgãos, entidades ou instituições legalmente constituídas, reconhecidas como representativas de diferentes setores usuários de 
recursos hídricos devidamente cadastrados junto ao SERH.

A proposta de criação dos comitês, quando encaminhada ao Conselho Estadual de Recursos Hídricos - CERH/PR deve conter, obrigatoriamente a justificativa da criação, diagnóstico da situação dos recursos hídricos e conflitos entre usos e usuários, além da caracterização sócio-econômica da área de atuação com identificação dos setores usuários de recursos hídricos e de sua importância relativa na região. Também deve indicar a proposta de composição do Comitê, segundo os critérios dispostos no Capítulo II (Art.4\%). Aos Comitês de Bacia Hidrográfica, no âmbito de sua área de atuação, observadas as deliberações pertinentes do Conselho Estadual de Recursos Hídricos (CERH/PR), ficaram estabelecidas competências diretamente ligadas ao funcionamento do Sistema Estadual (Decreto 2315, Capítulo III, 2000)

Os Comitês de Bacia Hidrográfica aprovarão seu Regimento Interno, no qual serão definidas as atribuições dos membros, as condições para a garantia das deliberações e tomadas de decisão com a maior transparência possível, a convocação ampla e prévia leitura dos documentos pelos conselheiros, as normas para a organização do Comitê, o funcionamento de suas plenárias, as condições para a participação, a constituição e funcionamento de câmaras técnicas e a organização básica de constituição e funcionamento de câmaras técnicas e a organização básica de apoio necessário ao exercício de sua Secretaria Executiva.

O decreto determina ainda que os conselheiros não terão nenhum tipo de remuneração por suas atividades no Comitê. Os encargos com a prestação de apoio técnico, administrativo e financeiro aos Comitês de Bacia Hidrográfica, assim como as demais atribuições inerentes às Unidades Executivas Descentralizadas, poderão ser exercidas por consórcios ou associações intermunicipais de bacias hidrográficas, por associações regionais, locais ou setoriais de usuários de recursos ou por Agências de Água, tal como definidas pela Lei Federal n. ${ }^{\circ}$ 9.433/97 e respectivo regulamento.

\subsection{Composição dos Primeiros Comitês de Bacia}

Com base no arcabouço jurídicoinstitucional do SERH, no final de 2005 iniciou-se a criação dos primeiros Comitês de Bacia e até o início do ano de 2009, havia sido criados cinco dos doze Comitês previstos pela Resolução 49/06. Cabe ressaltar que cada um destes comitês teve seu processo de solicitação, implementação e funcionamento, como resultado dos interesses específicos de acordo com a realidade de cada bacia hidrográfica. Nestes comitês, os setores estão distribuídos conforme o estabelecido a Lei Estadual 12.729/99, nas seguintes proporções:

TABELA 01 - COMPOSICAO DOS COMITES APROVADOS PELO CONSELHO ESTADUAL DE RECURSOS HIDRICOS

\begin{tabular}{|c|c|c|c|c|c|c|c|c|c|c|c|}
\hline \multicolumn{2}{|c|}{ COMPOSIÇÃO } & \multicolumn{2}{|c|}{$\begin{array}{l}\text { A. Iguaçu e A. } \\
\text { Ribeira }\end{array}$} & \multicolumn{2}{|c|}{ Tibagi } & \multicolumn{2}{|c|}{ Jordão } & \multicolumn{2}{|c|}{ Paraná III } & \multicolumn{2}{|c|}{$\begin{array}{l}\text { Pirapó } \\
\text { Paranapanema } \\
\text { III e IV }\end{array}$} \\
\hline $\begin{array}{l}\text { Poder } \\
\text { Publico }\end{array}$ & Ate $40 \%$ & 11 & $27,5 \%$ & 14 & $35 \%$ & 09 & $39 \%$ & 13 & $39,4 \%$ & 12 & $33,3 \%$ \\
\hline Usuários & Ate $40 \%$ & 16 & $40 \%$ & 16 & $40 \%$ & 09 & $39 \%$ & 13 & $39,4 \%$ & 12 & $33,3 \%$ \\
\hline $\begin{array}{l}\text { Sociedade } \\
\text { Civil }\end{array}$ & Min. $20 \%$ & 13 & $32,5 \%$ & 10 & $25 \%$ & 05 & $22 \%$ & 17 & $21,2 \%$ & 12 & $33,3 \%$ \\
\hline Total & $100 \%$ & 40 & $100 \%$ & 40 & $100 \%$ & 23 & $100 \%$ & 33 & $100 \%$ & 36 & $100 \%$ \\
\hline
\end{tabular}

FONTE: SUDERHSA, 2008.

O Comitê de Bacia do Alto Iguaçu e Afluentes do Alto Ribeira - COALIAR - foi o primeiro a se organizar. Sua história iniciou após o Decreto no 5.304/2002. No entanto, neste momento se tratava de um Comitê de rios até então de domínio da união. Em 2004, com base na resolução no 399, 
o rio Iguaçu passa ser considerado de domínio estadual. Em 2005 ele assume a atual forma e por meio do Decreto 5.878/2005, sendo composto por 38 membros, distribuídos na seguinte proporção:

TABELA 02: REPRESENTAÇÃO SETORIAL NO COMITÊ DE BACIA DO ALTO IGUAÇU E AFLUENTES DO ALTO RIBEIRA

\begin{tabular}{|lcl|}
\hline SETOR & MEMBROS & Estado do Paraná REPRESENTAÇÃO \\
& 5 & Municípios \\
Usuários de Recursos Hídricos & 3 & Abastecimento de água e diluição de efluentes urbanos \\
& 2 & Hidroeletrecidade \\
& 6 & Captação industrial e diluição de efluentes industriais \\
& 2 & Agropecuária e irrigação, inclusive psicultura \\
Sociedade Civil Organizada & 1 & Drenagem e resíduos sólidos urbanos \\
& 3 & Organizações não-governamentais \\
& 3 & Entidades de ensino e pesquisa \\
& 3 & Entidades técnico-profissionais \\
& 3 & Colegiados \\
& 38 & \\
& &
\end{tabular}

Fonte: DECRETO 2980/08

O Comitê de Bacia Hidrográfica do Rio Jordão foi instituído pelo Decreto no 5791/2002, sendo o seu pedido formalizado por meio de ofício assinado pela SANEPAR, CPEL Geração S.A e Santa Maria
- Cia de Papel e Celulose em 2001. O mesmo ato que criou o Comitê designou sua composição e proporções setoriais a saber:

TABELA 03: REPRESENTAÇÃO SETORIAL NO COMITÊ DE BACIA DO RIO JORDÃO

\begin{tabular}{|lcl|}
\hline \multicolumn{1}{|c|}{ SETOR } & MEMBROS & \multicolumn{1}{c|}{ REPRESENTAÇÃO } \\
Poder Público & 3 & Estado do Paraná \\
& 6 & Municípios \\
Usuários de Recursos & 1 & Abastecimento de água e diluição de efluentes urbanos \\
Hídricos & 2 & Hidroeletrecidade \\
& 3 & Captação industrial e diluição de efluentes industriais \\
Sociedade Civil Organizada & 1 & Agropecuária e irrigação, inclusive psicultura \\
& 1 & Drenagem e resíduos sólidos urbanos \\
& 1 & Lazer, recreação e outros usos não consuntivos \\
& 2 & Organizações não-governamentais \\
& 2 & Entidades de ensino e pesquisa \\
& 1 & Entidades técnico-profissionais \\
\hline
\end{tabular}

Fonte: DECRETO 5791/02 
O Comitê de Bacia Hidrográfica do Rio Tibagi foi instituído pelo Decreto no $5790 / 2002$ e neste mesmo ato foram designados os representantes, com mandato de dois anos, com a seguinte composição:

TABELA 04: REPRESENTAÇÃO SETORIAL NO COMITÊ DE BACIA DO RIO TIBAGI

\begin{tabular}{|lcl|}
\hline \multicolumn{1}{|c|}{ SETOR } & MEMBROS & \multicolumn{1}{c|}{ REPRESENTAÇÃO } \\
Poder Público & 1 & União \\
& 4 & Estado do Paraná \\
Usuários de Recursos & 9 & Municípios \\
Hídricos & 2 & Abastecimento de água e diluição de efluentes urbanos \\
& 4 & Hidroeletrecidade \\
& 2 & Captação industrial e diluição de efluentes industriais \\
Sociedade Civil Organizada & 2 & Drenagem e resíduos sólidos urbanos \\
& 1 & Lazer, recreação e outros usos não consuntivos \\
& 2 & Organizações não-governamentais \\
& 4 & Entidades de ensino e pesquisa \\
& 3 & Entidades técnico-profissionais \\
& 1 & Conselho Indígena
\end{tabular}

Fonte: DECRETO 5790/02

O Comitê de Bacia Hidrográfica do Rio Paraná III, foi instituído pelo Decreto $\mathrm{n}^{\circ}$ 2924/2004, o referido decreto indicou atribuições, designou representantes dos setores e suas proporcionalidades, com a seguinte composição:

TABELA 05: REPRESENTAÇÃO SETORIAL NO COMITÊ DE BACIA DO RIO TIBAGI

\begin{tabular}{|lcl|}
\hline \multirow{3}{*}{ SETOR } & MEMBROS & Rnião \\
& 1 & REPRESENTAÇÃO \\
& 6 & Estado do Paraná \\
Usuários de Recursos Hídricos & 6 & Municípios \\
& 3 & Abastecimento de água e diluição de efluentes urbanos \\
& 1 & Hidroeletrecidade \\
& 3 & Captação industrial e diluição de efluentes industriais \\
Sociedade Civil Organizada & 3 & Agropecuária e irrigação, inclusive psicultura \\
& 1 & Drenagem e resíduos sólidos urbanos \\
& 2 & Lazer, recreação e outros usos não consuntivos \\
& 2 & Organizações não-governamentais \\
& 1 & Entidades de ensino e pesquisa \\
& 1 & Comunidade Indígena \\
& 1 & Área de Proteção Ambiental \\
& 33 & \\
\hline
\end{tabular}

Fonte: DECRETO 2924/04 
O Comitê das Bacias dos Rios Pirapó, Paranapanema III e IV foi instituído pelo Decreto no $2245 / 2008$ em resposta à solicitação apresentada em conjunto pela sociedade civil, os usuários de RH e os poderes públicos da bacia sob a denominação de "Assossiação Pró Comitê da Bacia do Pirapó". O decreto definiu os participantes e proporções específicas nas seguintes condições:

TABELA 06: REPRESENTAÇÃO SETORIAL NO COMITÊ DE BACIA DO RIO PIRAPÓ, PARANAPANEMA III e IV.

\begin{tabular}{|lcl|}
\hline SETOR & MEMBROS & \multicolumn{1}{c|}{ REPRESENTAÇÃO } \\
Poder Público & 6 & Estado do Paraná \\
& 10 & Municípios \\
Usuários de Recursos & 4 & Abastecimento de água e diluição de efluentes urbanos \\
Hídricos & 1 & Hidroeletrecidade \\
Sociedade Civil Organizada & 6 & Captação industrial e diluição de efluentes industriais \\
& 5 & Agropecuária e irrigação, inclusive psicultura \\
& 2 & Organizações não-governamentais \\
& 2 & Entidades de ensino e pesquisa \\
& 40 & Entidades técnico-profissionais \\
\hline
\end{tabular}

Fonte: DECRETO 2245/08

1.1. Análises Preliminares nos Documentos Produzidos pelos Comitês. A análise de parte da documentação produzida pelos referidos Comitês permitiu conhecer dinâmicas do processo de implantação e início do funcionamento destes organismos. Deste modo, foram analisadas 06 (seis) Atas de reuniões do Comitê do Alto Iguaçu e Afluentes do Alto Ribeira entre 26/05/2006 e 06/08/2008; e 08 (oito) Atas de reuniões do Comitê do Paraná III produzidas entre 27/11/2004 e $03 / 06 / 2008$, que se encontram disponibilizadas até o momento nas páginas eletrônicas do órgão gestor estadual (SUDERHSA - atual Instituto de Águas do Paraná - www.suderhsa.pr.gov.br ).

As referidas Atas foram planificadas em tabelas analíticas de "Demandas e Decisões do Comitê de Bacia Hidrográfica", com os seguintes itens: Data, No da Reunião, Item de Pauta, Posição Setorial, Resultado e Encaminhamentos do Comitê.

Observando os resultados tabulados foi possível perceber que o COALIAR apresentou maior extensão textual por ATA em relação à Paraná III, bem como maior número de intervenções dos vários setores nas reuniões. Destacouse o fato ocorrido na $3^{a}$ Reunião Ordinária do
COALIAR (12dez2006, linhas 46 - 167), quando um dos seus membros teve suspensão 1 ano, por levantar acusações e insinuações contra várias organizações representadas no Comitê em rede internacional de computadores. Vários trechos desta ATA revelam alto grau de discussão política, jurídica e técnica desse fato e o registro detalhado no documento permite medir relações de conflito e consenso no decorrer da reunião.

As Atas do Comitê da Bacia do Paraná apresentaram poucos registros de manifestação dos conselheiros, em geral ocorrem apresentações dos temas pelos representantes do poder público sobre ações de suas esferas e poucas manifestações dos participantes. Em geral são registradas aprovações coletivas sem debates, questionamentos ou decisões conflituosas. A falta deste registro dificulta conhecer as posições setoriais e/ou individuais dos conselheiros.

A análise preliminar dos documentos produzidos pelos Comitês citados revelou que é possível identificar as demandas setoriais na medida em que estas são manifestadas e registradas, seja na forma de opiniões durante as reuniões, como nas discussões e votações sobre os temas da pauta e nas decisões tomadas. No entanto, a falta de registro detalhado nas ATAs, 
ora por falta do diálogo e o não registro, ora pelo registro superficial do diálogo, pode não expressar claramente as relações que ocorrem nas reuniões. 0 acesso ao conjunto da documentação dos Comitês ainda não foi completado, devido à precariedade da disponibilização dos mesmos pelos Comitês ao público, uma vez que somente alguns comitês disponibilizam informações por meio digital. Neste sentido, buscaram-se metodologias auxiliares como a observação direta das reuniões e entrevistas individuais com os atores envolvidos, que serão fundamentais na continuidade do estudo. Com a utilização de uma ferramenta de criação de formulários eletrônicos (LimeSurvey) foi gerado questionário indicadores de desempenho institucional do coaliar - comitê de bacias hidrográficas do alto iguaçu e afluentes do alto ribeira para coleta de dados e análise de processos institucionais dos Comitês de Bacia Hidrográfica do Estado do Paraná, como parte da metodologia da pesquisa de doutoramento, em desenvolvimento no Programa de Pós Graduação em Geografia da UFPR, na linha de Paisagem e Análise Ambiental 2007-2011. Os dados solicitados referemse exclusivamente ao trabalho dos membros titulares e suplentes que atuaram ou atuam no COALIAR, desde sua instituição pelo Decreto Estadual no 5.878 de 13 de dezembro de 2005.

\section{CONSIDERAÇÕES FINAIS}

Nesta abordagem admite-se a hipótese de que a qualidade da gestão da água empreendida por um Comitê resulta da qualidade das relações entre os diferentes atores sociais sobre uma dada bacia hidrográfica. Assim, as ações individuais e coletivas nos comitês se apresentam como a expressão do trabalho, energia ou empenho para garantir os diferentes interesses frente aos usos da água, e permitem conhecer as relações de poder e as resistências no processo da gestão hídrica. Os atores são ao mesmo tempo individuais e coletivos, pois suas atuações nos comitês resultam de suas relações sociais sobre o território, suas intenções e objetivos, definem sua identidade territorial e expressam estas relações.

Da mesma forma que se pode explicar as relações de poder na gestão do comitê, é possível também explicar as relações da gestão com a realidade ambiental da bacia. Dito de outro modo, é possível conhecer a materialidade das ações setoriais sobre a superfície da bacia, identificando os atores locais, suas formas de organização social e as intervenções no território. A abordagem territorial da gestão da água representa uma forma analítica de interpretação das variáveis que formam e transformam o Território, na perspectiva da gestão hídrica.

A análise das ações dos diversos atores e segmentos do poder público, dos usuários da água e da sociedade civil organizada nos comitês permite a produção de indicadores de avaliação do desenvolvimento territorial e aplicação de instrumentos de análise da qualidade da gestão da bacia hidrográfica, com vista ao cumprimento das metas e diretrizes estabelecidas nas políticas públicas vigentes.

\section{Bibliografia}

ABERS, Rebecca; JORGE, Karina Dino. Descentralização da gestão da água: por que os comitês de bacia estão sendo criados? Ambiente \& sociedade. v.8 n.2 Campinas jul./dez. 2005.

ASSUNÇÃO. F. N. A e BURSZTYN, Ma A. As políticas públicas das águas no Brasil. Acesso em 29 jan 2005. Documento não paginado. Disponível em: www.aguabolivia.org/situacionaguaX/IIIEncAguas/ conteúdo/trabajos_azul/TC-127.htm

BARLOW, M. \& CLARKE, T. OURO AZUL: como as grandes corporações estão se apoderando da água doce do nosso planeta. São Paulo : M. Books do Brasil, 2003.

BERTRAND, C \& BERTRAND, G. Uma Geografia Transversal e de Travessias . (Org. Trad. PASSOS, Messias Modesto) Ed. Massoni : Maringá, 2007.

BERTRAND, G. Paisagem e Geografia Física Global: esboço metodológico. Caderno de Ciências da Terra, São Paulo, n. 13, 27 p., 1971. 
. Le paysage entre la nature et la société. Revue Géographique des Pyrénées et du SudOuest, Toulouse, v. 49, n. 2, p. 239-258, 1978.

BOLÓS y CAPDEVILA, M. (org.) Manual de ciencia del paisage: teoria, metodos y aplicaciones. Barcelona: Masson, 1992.

BRASIL. Lei n. 9.433 - 08 jan.1997. Institui a Política Nacional de Recursos Hídricos, cria o Sistema Nacional de Gerenciamento de Recursos Hídricos.

CHRISTOFOLETTI, A. Significância da teoria de sistemas em Geografia Física. Boletim de Geografia Teorética, Rio Claro, v. 16-17, n. 31-34, p. 119128, 1986-1987.

A geografia física no estudo das mudanças ambientais. In: Becker, B. et al (org.) Geografia e meio ambiente no Brasil. São Paulo: Hucitec, 1995 , p. 334-345.

Modelagem de sistemas ambientais. São Paulo: Edgard Blücher, 1999, 236 p.

DEMATTEIS, Giuseppe. Suburbanización y periurbanización: ciudades anglosajonas y ciudades . Rio de Janeiro: Civilização Brasileira, 1994.

Contesti Locali e grandi insfrastrutture. Politiche e progretti in Itália e in Europa. Franco Angeli. Milão : Itáli, 2001

GONZÁLEZ, S. La geografía escalar del capitalismo actual. In: Geo Crítica Scripta Nova. REVISTA ELECTRÓNICA DE GEOGRAFÍA Y CIENCIAS SOCIALES Universidad de Barcelona. ISSN: 11389788. Depósito Legal: B. 21.741-98 Vol. IX, núm. 189, 15 de mayo de 2005. Acesso em 08 de set de 2007. Disponível em http://www. ub.es/geocrit/sn/sn-189.htm

HAESBAERT, R. RS: latifúndio e identidade regional. Porto Alegre: Mercado Aberto, 1988.

HAESBAERT, R. Des-territorialização e identidade: a rede "gaúcha" no nordeste. Niterói: EDUFF, 1997.

HAESBAERT, R. Identidades territoriais. In: ROSENDAHL, Z.; CORREA, R. L. (Org.) Manifestações da cultura no espaço. Rio de Janeiro: EdUERJ, 1999. p.169-190.

HAESBAERT, R.; SANTA BÁRBARA, M. de. J. Identidades e migração em áreas transfronteiriças. GEOgraphia, Niterói, n.5, p. 43-60, 2001.

LANNA, A. E. L. Gerenciamento de bacia hidrográfica: aspectos conceituais e metodológicos. Brasília: Instituto Brasileiro do Meio Ambiente e dos Recursos Naturais Renováveis, 1995. 171 p.

LÉVI-STRAUSS, C. O Útimo Festim de Esopo. São Paulo : Octavio Paz, Perspectiva, São Paulo, 1977.

MAGALHÃES JR. A. P. Indicadores ambientais e recursos hídricos: realidade e perspectivas para o Brasil a partir da experiência francesa. Ed. Bertrand Brasil : Rio de Janeiro, 2007.

PARANÁ. Comitê de Bacia Hidrográfica do Alto Iguaçu e Afluentes do Alto Ribeira. Ata da $2^{a}$ Reunião Ordinária, de 26mai2006. Secretaria Executiva, Curitiba, PR.

- Comitê de Bacia Hidrográfica do Alto Iguaçu e Afluentes do Alto Ribeira. Ata da $3^{a}$ Reunião Ordinária, de 01out2007. Secretaria Executiva, Curitiba, PR.

- Comitê de Bacia Hidrográfica do Alto Iguaçu e Afluentes do Alto Ribeira. Ata da Reunião 4a Ordinária, de 12dez2006. Secretaria Executiva, Curitiba, PR.

. Comitê de Bacia Hidrográfica do Paraná III. Ata da $1^{\text {a }}$ Reunião Ordinária, de 27nov2004. Secretaria Executiva, Foz do Iguaçu, PR.

.Comitê de Bacia Hidrográfica do Paraná III. Ata da $2^{a}$ Reunião Ordinária, de 07abr2005. Secretaria Executiva, Foz do Iguaçu, PR.

.Comitê de Bacia Hidrográfica do Paraná 
III. Ata da Reunião $3^{a}$ Reunião Ordinária, de 29jun2005. Secretaria Executiva, Foz do Iguaçu, PR.

- Constituição do Estado do Paraná. Assembléia Legislativa. Curitiba, 1989.

Decreto Estadual no 2.315/00. Regulamenta os Comitês de Bacia Hidrográfica. Diário Oficial do Estado. Curitiba, 18 jul. 2000b

Decreto Estadual no 5304 de 05 de fevereiro de 2002. Instituí o Comitê das Bacias do Alto Iguaçu/Alto Ribeira, através da designação de representantes do Poder Público, Setores Usuários de Recursos Hídricos, Sociedade Civil Organizada Secretaria de Estado do Meio Ambiente e Recursos Hídricos - SEMA.Curitiba, 2002.

. Decreto Estadual no 5790 de 13 de junho de 2002. Institui o Comitê da Bacia do Rio Tibagi e designa seus integrantes. Curitiba, 2002.

. Decreto Estadual no 5791 de 13 de junho de 2002. Institui o Comitê da Bacia do Rio Jordão e designa seus integrantes. Curitiba, 2002.

. Decreto Estadual no 2924 de 05 de maio de 2004. Institui o Comitê da Bacia do Paraná III. Curitiba, 2004.

Decreto Estadual no 5878 de 13 de dezembro de 2005. Institui o Comitê das Bacias do Alto Iguaçu e Afluentes do Alto Ribeira. Curitiba, 2005.

.Decreto Estadual n02245 de 03 de março de 2008. Institui o Comitê do Piraponema. Curitiba, 2008.

Lei Estadual n 6.938 de 21 de outubro de 1977. Constitui a Companhia de Minaração do Paraná - MINEROPAR. Curitiba, 1977.
. Lei Estadual no 12.726, de 26 de novembro de 1999. Lei do Sistema Estadual de Recursos Hídricos: Institui a Política Estadual de Recursos Hídricos e cria o Sistema Estadual de Gerenciamento de Recursos Hídricos do Paraná. Curitiba: Assembléia Legislativa do Estado do Paraná, 26 nov. 1999. 14p.

- Lei Estadual no 16.242, de 13 de outurbro de 2009. Cria o Instituto das Águas do Paraná - ÁGUASPARANÁ, como autarquia do Estado - vinculada a Secretaria Estadual do Meio Ambiente - que substitui a Superintendência de Desenvolvimento de Recursos Hídricos e Saneamento Ambiental (SUDERHSA). Curitiba, 2009

PASSOS, M. M. dos. Biogeografia e paisagem. Presidente Prudente: FCTUNESP,1998. . Por uma história ecológica da paisagem.

Geografia em atos, n. 1, v. 1, 1998, p. 87-109.

RAFFESTIN, Claude. Por uma geografia do poder. Tradução de Maria Cecília França. São Paulo: Ática, 1993.

(2005) A ordem e a desordem ou os paradoxos da fronteira. In: OLIVEIRA, Tito Carlos M. de. (org.). Território sem limites: estudos sobre fronteiras. Campo Grande-MS: Editora da UFMS, p. 9-15.

RIBEIRO, W.C. Geografia política da água. Annablue : São Paulo, 2008.

SAQUET, Marcos Aurélio. O território: diferentes interpretações na literatura italiana. In: RIBAS, A. D.; SPOSITO, E. S.; SAQUET, M. A. Território e Desenvolvimento: diferentes abordagens. Francisco Beltrão: Unioeste, 2004.

SAQUET, Marcos Aurélio. Abordagens e concepções de território. São Paulo: Expressão popular, 2007. 
SENADO FEDERAL. Constituição da República Federativa do Brasil. Brasília: Centro Gráfico do Senado Federal, 1988. 292p.

SMITH, N. Contornos de uma política espacializada: veículos dos sem-teto e produção da escala geográfica. In: ARANTES, A. (org) O Espaço da diferença. Campinas : Papirus, 2000.

SOTCHAVA, V. B. Définition de quelques notions et termes de Géographie Physique. Dokl. Institute de Géographie de la Sibérie et Extrême Orient, n. 3, p. 94-117, 1962.

. O estudo de geossistemas. Métodos em Questão, São Paulo, n. 16, 52 p., 1977.

Por uma teoria de classificação de geossistemas de vida terrestre. Biogeografia, São Paulo, n. 14, 24 p., 1978. 